\title{
Mapping International Trade and Supply Chains for Humanitarian and Business Resilience to Atmospheric and Pandemic Disasters Method and Preliminary Findings for Puerto Rico ${ }^{1}$
}

\author{
Maribel-Aponte García \\ University of Puerto Rico-Rio Piedras \\ Carlos A. Alvarez \\ University of Puerto Rico-Mayaguez
}

\begin{abstract}
The study presents preliminary findings of a Pilot Project that identified alternatives to disruptions in international trade and supply chains in the face of atmospheric (hurricane Maria in 2017) and pandemic (COVID-19) disasters. It focused on four critical imports: water, humanitarian relief goods, solar photovoltaic products, and COVID-19 test reagents. The project proposed an alternative pathway and method to address disruptions: build an integrated database from Bill of Lading and import-export-related data organized by Harmonized Schedule Code. Data analyses were carried out based on the Harmonized Tariff Schedule code system, and an integrated database was generated for imports of the four products that Puerto Rico buys in the international market. Import Key data were analyzed based on the Bill of Lading, sector, companies that sell the product, location of countries where the products are sold, ports that can reach Puerto Rico, and contact information of the companies and suppliers. This information allows humanitarian organizations, SMEs and the government to identify alternative supply networks.
\end{abstract}

Keywords: bill of lading, resilient supply chains, humanitarian resilience to disasters, business resilience to disasters, Puerto Rico

\section{INTRODUCTION}

This research presents preliminary findings of a Pilot Project that identifies alternatives to disruptions in international trade and supply chains in the face of atmospheric and pandemic disasters. The Pilot Project focused on four critical imports: water, humanitarian relief goods, solar photovoltaic products, and COVID19 test reagents. A quantitative exploratory study was designed to mine international trade databases and identify alternative sources of supply chains and networks to help increase the resilience of humanitarian organizations and small and medium-sized enterprises (SMEs) in Puerto Rico.

In 2010, Aponte García began to develop the method of chain analysis in international trade. In 2015, she founded the Mapping of Businesses and Chains in International Trade project. Since then, she has applied the method to different areas (hydrocarbons, minerals, green chains, SME exports and food sustainability), generating research under local and international grants and collaborations. ${ }^{2}$ 


\section{BACKGROUND}

For islands, building resilience capacities in international trade and supply chains is crucial in the context of disasters, both for humanitarian organizations and government as well as businesses.

Hurricane Maria struck Puerto Rico on September 20, 2017. Communications and the electrical service system completely collapsed; leaving the government unable to coordinate the logistics of water, food and petroleum product distribution; and the private sector paralyzed. For several weeks, the ports and harbors of San Juan, Puerto Rico and Jacksonville, Florida were unable to ship and/or distribute critical and indispensable supplies. The closure of the Jacksonville port demonstrated how dependence on imports threatens Puerto Rico's supply chains, since the island imports $85 \%$ of the food it consumes.

The effect of atmospheric disasters on the population and businesses, especially Small and Medium Enterprises (SMEs), have been devastating. In the weeks following September 20, 2017, approximately three to five thousand people died. In addition, more than 300,000 Puerto Ricans migrated to Florida (9\% of the island's population). Between 80 and $90 \%$ of the 45,000 SMEs (which generate $83 \%$ of employment and 53\% of the Gross Domestic Product ${ }^{3}$ ), became inoperative. Some estimates state that between 5,000 and 10,000 companies will never resume operations. Agriculture was destroyed, with $50-80 \%$ of crops lost. Federal Emergency Management Agency (FEMA) supplies were slow to arrive and disaster relief has been stalled for years. The January 2020 earthquakes destroyed businesses in the southern part of the island and further exacerbated the already difficult situation.

After March 2020, as SMEs and HROs in Puerto Rico went into lockdown, health issues on farms and production sites, temporary trade measures enacted by international government authorities in relation to the COVID-19 pandemic and U.S. sanctions imposed on Asian suppliers, affected port activity and disrupted food and health supply chains. SMEs closed down temporarily or permanently, tens of thousands of people faced unemployment in an island already confronting severe poverty rates $(43.1 \%$ in 2018 , much higher than the U.S. national rate of $13.1 \%)^{4}$, inequality (Gini coefficient was .55 in 2019) ${ }^{5}$ and shrinking economic activity and trade. As of March 1, 2021, Puerto Rico has 2,037 confirmed deaths, and 92,708 confirmed cases. ${ }^{6}$ The number of unemployed increased dramatically, estimated at 76,000 people in July 2020, and 94,200 in December 2020. ${ }^{7}$ Since Puerto Rico exports and imports most goods to/from ports along the U.S. coastline, the effects of the 2020 hurricane season further affected supply chains, as ten storms struck along the Gulf Coast between Texas and the Florida Panhandle. ${ }^{8}$

In disaster contexts, there are two crucial steps in building resiliency, according to the Massachusetts Institute of Technology's Disaster Supply Chain Institute (see Meyer and Meyer, 2017). For each step, there is a gap for SMEs established in Puerto Rico. The first step is to Map and Understand the System, mapping critical supply chains and infrastructure to understand where critical goods come from and how they might move down the chain to an area affected by disaster. The second step is to map supply chains by using billof-materials (BOMs, list of all the materials and parts that a manufacturer needs to create a certain good) to understand the implications of supplier disruptions. This step is mostly available for large companies with inventory management or that use third-party supply chain risk management services that gather information on suppliers' geographic locations.

But SMEs and HROs don't have a Map of Trade and Supply Chains nor a Bill of Materials. To solve this problem, this project proposed an alternative pathway and method: build an integrated database from Bill of Lading, and import-export related data organized by Harmonized Schedule Code, to build supply-chain-trade capabilities to address disruptions.

\section{CONTRIBUTIONS OF THIS RESEARCH TO THE ISSUE OF RESILIENCE IN PUERTO RICO}

At present, there is no method of analysis linking annual data on international trade, supply chains and companies. Analyses of simultaneous global disruptions in supply chains are an under-researched topic. Puerto Rico, like many other countries, does not have an integrated international trade database with information on local and international firms. The literature on the effects of natural disasters on businesses, options and strategic plans in the face of disasters is also scarce. 
The method has generated an integrated commercial database for Puerto Rico, based on USA Trade Online data and U.S. Trade with Puerto Rico and U.S. Possessions' Reports ${ }^{9}$ and supply chain maps/diagrams based on Importkey database. For the selected group of products, imports were analyzed in order to identify alternative supplier networks; and exports were analyzed as an indicator of the capacity of local suppliers to meet domestic demand.

Data analyses were carried out based on the Harmonized Tariff Schedule code system; and an integrated database was generated for imports of the four products that Puerto Rico buys in the international market. Importkey data were analyzed based on Bil of Lading information by product; sector; companies that sell the product in the international market; countries in which the companies that sell the products are located; ports through which these products can reach Puerto Rico; and the address and contact information of the companies and suppliers. This information allows humanitarian organizations, SMEs and the government to identify alternative supply networks.

For each product, supplier network alternatives were identified in the face of potential disruptions in trade value chains based on Bill of Lading reports: region, foreign receiving port, foreign shipping port, buyer and supplier. Tables and diagrams-maps of import suppliers and export markets were then generated.

Among the preliminary findings, the following are noteworthy:

- The Greater Caribbean constitutes an alternative network in supply chains, which has proved crucial in disasters, not only for businesses, but also for humanitarian relief organizations. When disasters strike, rapid response depends on the ports of the Greater Caribbean, including, crucially, those of the Dominican Republic, Mexico, Trinidad and Tobago and the Virgin Islands.

- The United States also plays an important role, using receiving and shipping ports in the Caribbean and Central America as an alternative supplier network.

- Airfreight logistics could strengthen humanitarian logistics for relief goods supplies.

- Puerto Rico was shown exporting donations of medicines and drugs in 2017 and 2018. In addition, it is shown exporting COVID-19 test reagents in 2020, a paradoxical fact in the context of the pandemic and the shortage of these products on the Island. ${ }^{10}$

- In the case of relief goods, during 2017, the role of the Caribbean proved crucial both as a receiving and shipping port. Humanitarian organizations and federal emergency agencies stand out as buyers of these goods. Among the most important buyers was FEMA, which imported many of the supplies from China and the Virgin Islands.

- Solar products were imported mainly from Asia and the United States.

- The water product is divided into three: mineral, "ordinary" and "relief" water. Mineral water comes from Europe and is more expensive. "Ordinary" water, a very scarce commodity after the hurricane, is imported mainly from the United States and Canada. Water as a humanitarian relief good was imported mainly from the Caribbean and Mexico. All ports of shipment turned out to be in the Greater Caribbean, including the Dominican Republic, Mexico, Trinidad and Tobago, and the Virgin Islands.

\section{CONCLUSION}

The method has generated an integrated trade database for Puerto Rico and supply chain maps/diagrams. The Pilot Project provided preliminary findings that shed light on how to build resilience. The analysis can be extended to product groups according to validated lists of essential critical products classified by Harmonized Tariff Schedule code. Alternative supplier networks in the Greater Caribbean help build resilience in the context of complex atmospheric and pandemic disasters.

\section{ACKNOWLEDGEMENT}

Translated \& edited by American Publishing Services (https://americanpublishingservices.com/). 


\section{ENDNOTES}

1. This research project was funded by a grant from the Business Innovation and Resilience Program of the Puerto Rico Science, Technology and Research Trust. We would like to acknowledge the support of Annie Mustafa, Program Manager and Gilberto Guevara, Program Director.

2. Many of these papers are available in open access at https:/urrp.academia.edu/; and $<$ https://maribelapontegarcia.com $>$.

3. http://sincomillas.com/las-empresas-locales-generan-el-83-del-empleo-y-el-53-del-pib/

4. https://www.census.gov/library/stories/2019/09/puerto-rico-outmigration-increases-povertydeclines.html\#: :text=The\%20poverty\%20rate\%20in\%20Puerto,state\%20poverty\%20rates\%20in\%202018

5. https://www.statista.com/statistics/227249/greatest-gap-between-rich-and-poor-by-us-state/

6. http://www.salud.gov.pr/Pages/coronavirus.aspx

7. https://www.bls.gov/eag/eag.pr.htm

8. https://disasterphilanthropy.org/disaster/2020-atlantic-hurricane-season/

9. Census https://www.census.gov/library/publications/2020/econ/ft895-19.html

10. According to Hedgeclippers, "But as the country grapples with the COVID-19 pandemic, pharmaceutical companies, and the tests and reagents they produce, have had little presence in the crisis" (http://hedgeclippers.org/pain-and-profit-covid-19-profiteers-in-puerto-rico/, p. 3).

\section{REFERENCES}

Meyer, A., \& Meyer, D. (2017). Supply Chain Resilience: Restoring Business Operations After a Hurricane. Summary Report. Cambridge: Massachusetts Institute of Technology Center for Transportation \& Logistics. Retrieved from https://humanitarian.mit.edu/wpcontent/uploads/2019/12/ Supply-Chain-Resilience-Restoring-Business-Operations-After-aHurricane.pdf

U.S. Congressional Research Service. (2020, April 6). CSR Report R46304, COVID-19: China Medical Supply Chains and Broader Trade Issues. Retrieved from https://www.everycrsreport.com/fiR46304_eb118726bdc67022d3e8b0d09e76381b23e0a485.html\#_Toc37165319 